\title{
PENENTUAN HARGA JUAL OPSI BARRIER TIPE EROPA DENGAN METODE ANTITHETIC VARIATE PADA SIMULASI MONTE CARLO
}

\author{
Luh Hena Terecia Wismawan Putri ${ }^{1 \S}$, Komang Dharmawan ${ }^{2}$, I Wayan Sumarjaya ${ }^{3}$ \\ ${ }^{1}$ Jurusan Matematika, Fakultas MIPA - Universitas Udayana [Email: henaterecia01@ gmail.com] \\ ${ }^{2}$ Jurusan Matematika, Fakultas MIPA - Universitas Udayana [Email:dharmawan.komang@gmail.com] \\ ${ }^{3}$ Jurusan Matematika, Fakultas MIPA - Universitas Udayana [Email: sumarjaya@unud.ac.id] \\ ${ }^{\S}$ Corresponding Author
}

\begin{abstract}
ABSTARCT
The purpose of this research is to compare the selling price of down and out barrier option when the prices are simulated by the Antithetic Variate Monte Carlo and the standar Monte Carlo. Barrier options are path dependent options and the payoff depend on whether the underlying asset price touched the barrier or not during the life of the option. In this research, we conducted simulations against the closing price of the shares of PT Adhi Karya using Standard Monte Carlo simulation and the Monte Carlo-Antithetic Variate simulation. After the simulation, we obtained that the option prices using Antithetic Variate produces a cheaper price than the standar one. We also found that the analytic solution has a smaller error on its confidence interval compare to the Monte Carlo Standar.
\end{abstract}

Keywords: Barrier options, Standard Monte Carlo, Monte Carlo-Antithetic Variate

\section{PENDAHULUAN}

Instrumen yang diperdagangkan dan banyak diminati adalah opsi. Opsi merupakan perjanjian atau kontrak antara penjual opsi (seller atau writer) dengan pembeli opsi (buyer), di mana penjual opsi menjamin adanya hak tetapi bukan suatu kewajiban dari pembeli opsi, untuk membeli atau menjual suatu aset tertentu pada waktu dan harga yang telah ditetapkan, apabila saat waktu jatuh tempo (expiration date) pemegang opsi tidak menggunakan haknya, maka hak tersebut akan hilang dengan sendirinya (Tandelilin, 2010).

Secara umum opsi dibedakan menjadi dua yaitu opsi beli (call option) dan opsi jual (put option). Opsi berdasarkan waktu pelaksanaanya terbagi menjadi dua yaitu opsi tipe Amerika dan opsi tipe Eropa yang disebut dengan opsi standar (vanilla option). Selain itu, terdapat opsi alternatif yang lebih dikenal sebagai opsi eksotik (exotic option). Opsi eksotik adalah suatu opsi yang memiliki pembayaran tidak hanya bergantung pada harga aset saat dilaksanakan, tetapi juga bergantung pada harga aset selama umur opsi tersebut berlangsung. Seorang investor selain mengetahui opsi vanillaperlu juga mengetahui opsi eksotik. Salah satu jenis opsi eksotik adalah opsi barrier (barrier option). Ada beberapa metode yang digunakan dalam perhitungan harga opsi yaitu Black Scholes, binomial tree, trinomial KamradRitchken, Monte Carlo. Salah satu metode yang digunakan dalam perhitungan harga opsi adalah metode Monte Carlo.

Metode Monte Carlo didasarkan pada analogi probabilitas dan pembangkit bilangan acak (Glasserman, 2004). Metode Monte Carlo dibagi menjadi dua yaitu Monte Carlo Standard dan Monte Carlo Variance Reduction. Metode Monte Carlo Standar adalah sebuah teknik untuk menyelesaikan suatu masalah dengan menjalankan percobaan dalam jumlah banyak, yang disebut simulasi, untuk mendapatkan hasil yang paling mendekati dari percobaan yang dilakukan. Metode Monte Carlo Standar digunakan untuk perhitungan numerik yang mengandung integral multidimensi dalam 
komputasi keuangan (Boyle, 1997). Sedangkan metode Monte Carlo Variance Reduction merupakan perluasan dari metode Monte Carlo Standar dengan menggunakan teknik pengurangan varians (variance reduction techniques). Salah satu teknik pengurangan varians adalah teknik antithetic variate. Teknik antithetic variates adalah suatu cara yang digunakan untuk mengurangi varians dengan cara mengganti peubah acak dengan peubah acak lainnya yang berkorelasi negatif tanpa meningkatkan ukuran sampel dalam mensimulasi harga opsi (Wang \& Wang, 2011).

Penelitian terkait dengan teknik pengurangan varians (variance reduction techniques) dilakukan oleh Artanadi, et al. (2017) menghitung harga opsi beli tipe Asia dengan metode Monte Carlo-Control Variatedengan hasil penelitian, harga opsi tipe Asia lebih cepat menuju konvergen dengan metode Monte Carlo-control variate. Artini, et al., (2016) mengestimasi Value at Risk (VaR) pada opsi beli tipe Asia yang dihitung menggunakan metode imoportance sampling dengan hasil penelitian, perhitungan risiko opsi dengan alat ukur Value at Risk (VaR) lebih efektif menggunakan importance sampling. Berdasarkan penelitian yang telah dilakukan penulis tertarik untuk mengkaji lebih dalam teknik pengurangan varians khususnya antithetic variateyang diterapkan dalam menentukan harga jual opsi barrier tipe Eropa. Tujuan dari penelitian ini adalah mengetahui hasil perbandingan harga opsi pada simulasi Monte Carlo antithetic variate dan simulasi Monte Carlo standar.

Faktor-faktor yang memengaruhi harga opsi terbagi menjadi enam yaitu harga saham yang mendasari, harga pelaksanaan (strike price), waktu jatuh tempo, tingkat suku bunga bebas risiko, volatilitas dan deviden (Tandelilin 2010).

Nilai intrinsik adalah nilai yang bersifat ekonomis jika nilai opsi tersebut dilaksanakan (Fabozzi, 2000). Nilai intrinsik opsi dapat dibagi menjadi tiga yaitu:in the money adalah opsi yang menghasilkan, at the money adalah opsi yang harga pelaksanaannya sama dengan harga saham yang mendasari dan out the money adalah opsi yang tidak menghasilkan. Opsi jual (put option) akan mempunyai nilai intrinsik yang positif jika harga saham yang mendasari lebih kecil dari harga pelaksanaan. Persamaan matematis opsi jual dapat dinyatakan sebagai berikut:

$$
P_{t}=\max \left(K-S_{t}, 0\right)
$$

dengan $P_{t}$ menyatakan harga opsi jual (put option) pada waktu $t, S_{t}$ menyatakan harga saham pada waktu $t$, dan $K$ adalah harga pelaksanaan (strike price).

Opsi barrier (barrier options) adalah opsi yang payoff-nya bergantung pada apakah harga aset yang mendasari menyentuh barrier atau tidak selama masa hidup opsi. Menurut Lessy (2013) opsi barrier terbagi menjadi beberapa jenis yaitu: down and out, down and in, up and out, dan up and in. Opsi barrierdown and out adalah opsi yang hidup selama harga aset yang mendasari yaitu $S_{t}$ belum menyentuh nilai barrier $(H)$ dengan $S_{t}>H$, pada selang waktu [0,T]. Payoff dari opsi jual tipe barrier down and out saat jatuh tempo dapat dituliskan pada persamaan (2):

$$
\text { payoff }=\left\{\begin{array}{c}
\max \left(K-S_{t}, 0\right) \text { jika } S_{t} \leq H \\
0, \quad \text { jika } S_{t}>H
\end{array}\right.
$$

Selanjutnya, persamaan (2) didiskontokan menjadi:

$$
\text { Harga opsi }=e^{-r T} \max \left(K-S_{t}, 0\right)
$$

\section{Nilai Analitik Opsi Barrier}

Pada tahun 1973, Merton pertama kali menciptakan formula analitik untuk menghitung opsi barrier, selanjutnya formula analitik Merton dikembangkan oleh Reiner dan Rubinstein pada tahun 1991 menjadi delapan jenis dari opsi barrier (Jerome \& Keung, 2015). Setelah itu, Haug merekonstruksi formula dari Reiner dan Rubinstein menjadi lebih sederhana agar mudah untuk dihitung dengan tambahan variabel biner. Perhitungan nilai analitik opsi jual barrier down and out tanpadeviden $(q=0)$ dan tanpa rebate $(X=0)$ untuk $K>H$ sebagai berikut (Haug, 2007):

$$
\begin{aligned}
& \text { Nilai analitik opsi }=K e^{-r T}\left(N\left(-\alpha_{2}\right)-\right. \\
& N\left(-\alpha_{4}\right)+a\left(N\left(\alpha_{6}\right)-\right. \\
& \left.\left.N\left(\alpha_{8}\right)\right)\right)-S_{0}\left(N\left(-\alpha_{1}\right)-\right. \\
& N\left(-\alpha_{3}\right)+b\left(N\left(\alpha_{5}\right)-\right. \\
& \left.\left.N\left(\alpha_{7}\right)\right)\right)(4)
\end{aligned}
$$

dengan 


$$
\begin{aligned}
& a=\left(\frac{H}{S_{0}}\right)^{2\left(-1+\frac{2 r}{\sigma^{2}}\right)} \\
& b=\left(\frac{H}{S_{0}}\right)^{2\left(1+\frac{2 r}{\sigma^{2}}\right)}
\end{aligned}
$$

\section{Proses Wiener}

Proses Wiener merupakan salah satu bagian proses Markov dengan mean adalah nol dan variance rate satu per tahun. Secara formal, peubah $z$ mengikuti proses Wiener jika memiliki dua sifat sebagai berikut:

1. Perubahan $\Delta \mathrm{z}$ selama jangka waktu terkecil $\Delta \mathrm{t}$ adalah $\Delta \mathrm{z}=\varepsilon \sqrt{\Delta \mathrm{t}}$ dengan $\varepsilon \sim N(0,1)$

2. Nilai $\Delta \mathrm{z}$ untuk dua interval wktu yang berbeda saling bebas. Dalam hal ini mengikuti sifat pertama, dengan $\Delta z$ sendiri memiliki sebaran normal dengan rata-rata adalah 0 , simpangan baku adalah $\sqrt{\Delta t}$,dan ragam adalah $\Delta \mathrm{t}$.

Pada sifat nomor dua menunjukkan bahwa $z$ mengikuti proses Markov.

Pergerakan harga saham pada periode mendatang mengikuti model Gerak Brown Geometrik. Secara matematis dapat dituliskan sebagai berikut:

$$
S_{t}=S_{t 0} e^{\left[\left(r-\frac{\sigma^{2}}{2}\right) \Delta t+Z \sigma \sqrt{\Delta t}\right]}
$$

dengan $S_{t}$ merupakan harga saham pada saat mendatang, $S_{t 0}$ yaitu harga saham awal, $r$ adalah tingkat suku bunga, $\sigma$ merupakan volatilitas dan $Z$ bilangan acak berdistribusi normal $(Z \sim N(0,1))$.

Penentuan nilai return dengan metode log return dapat dihitung sebagai berikut:

$$
R_{t}=\ln \left(\frac{S_{t+1}}{S_{t}}\right)
$$

Rata-rata nilai return saham dapat dituliskan sebagai berikut:

$$
\overline{R_{t}}=\frac{1}{n} \sum_{t=1}^{n} R_{t}
$$

Volatilitas dinyatakan dengan simbol $\sigma$, apabila dinyatakan dalam bentuk kuadrat disebut dengan variance $\left(\sigma^{2}\right)$ yang dapat dihitung sebagai berikut (Husnan, 2001):

$$
\operatorname{var}\left(R_{t}\right)=\frac{1}{n-1} \sum_{t=1}^{n}\left(R_{t}-\overline{R_{t}}\right)^{2}
$$

Volatilitas tahunan dapat dihitung sebagai berikut:

$$
\sigma=\sqrt{\operatorname{var}\left(R_{t}\right) \times k}
$$

dengan $k$ merupakan banyaknya periode.

Simulasi Monte Carlo Standar, disebut juga Crude Monte Carlo, adalah suatu metode yang melibatkan pembangkit bilangan acak dengan distribusi probabilitas yang dapat diketahui dan ditentukan. Dasar simulasi Monte Carlo Standar adalah melakukan percobaan pada elemenelemen probabilistik melalui pengambilan sampel acak. Ekspetasi payoff dalam kondisi resiko netral dihitung dengan menggunakan prosedur sampling, kemudian didiskonto pada suku bunga bebas risiko. Penentuan harga opsi pada simulasi Monte Carlo dipengaruhi oleh harga opsi dalam keadaan risiko netral $(r=\mu)$. Dalam simulasi Monte Carlo Standar, harga opsi diasumsikan mengikuti Gerak Brown Geometrik.

Pada bagian Simulasi Monte Carlo-Antithetic Variatedi adaptasi dari (Wang \& Wang (2011). Anthitetic variate merupakan salah satu bagian dari teknik pengurangan varian yang ada pada simulasi Monte Carlo.Ide dasar teknik ini yaitu melibatkan perhitungan dua buah nilai opsi yaitu $S^{+}$dan $S^{-}$. Perhitungan harga opsi menggunakan teknik Antithetic variate mengikuti Gerak Brown Geometri yaitu dengan membangkitkan dua bilangan acak sebagai berikut:

Bangkitkan bilangan acak $Z_{1} \in$ $Z_{1} \sim N(0,1)$ dan $Z_{2} \in Z_{2} \sim N(0,1)$ kemudian hitung nilai penduga (estimator) yaitu:

$$
S^{+}=S_{t_{0}} e^{\left(r-\frac{\sigma_{t}^{2}}{2}\right) \Delta t+z \sigma \sqrt{\Delta t}}
$$

dan nilai penduga antithetic yaitu:

$$
S^{-}=S_{t_{0}} e^{\left(r-\frac{\sigma_{t}^{2}}{2}\right) \Delta t-Z \sigma \sqrt{\Delta t}}
$$

Nilai penduga akhirnya diketahui dengan menggabungkan kedua penduga yaitu:

$$
S_{\text {gabungan }}=\frac{S^{+}+S^{-}}{2}
$$

Pembentukan penduga antithetic bertujuan untuk membentuk penduga baru dengan varians lebih kecil. Diberikan varians dari Sgabunganyaitu:

$$
\begin{aligned}
& \operatorname{Var}\left(S_{\text {gabungan }}\right)=\operatorname{Var}\left(\frac{S_{+}+S_{-}}{2}\right) \\
& =\frac{\operatorname{Var}\left(S_{+}\right)+\operatorname{Var}\left(S_{-}\right)+2 \operatorname{Cov}\left(S_{+}, S_{-}\right)}{4}
\end{aligned}
$$


Nilai $\operatorname{Var}\left(S_{\text {gabungan }}\right)$ akan mengecil apabila nilai $\operatorname{Cov}\left(S_{+}, S_{-}\right)<0$. Dapat dilihat pada persamaan (13) dan (14) bahwa nilai keduanya bergerak berlawanan, yang berarti $\operatorname{Cov}\left(S_{+}, S_{-}\right)<0$.

Dengan demikian pembentukan penduga antithetic dapat digunakan untuk membentuk penduga baru yang memiliki varians yang lebih kecil.

Simulasi Monte Carlo-Antithetic Variate dalam menentukan harga opsi dapat diuraikan sebagai berikut:

1. Menetapkan variabel-variabel yang diperlukan dalam perhitungan yaitu yaitu nilai saham awal $\left(S_{0}\right)$, waktu jatuh tempo $(T)$, harga kesepakatan $(K)$, suku bunga bebas risiko $(r)$, nilai barrier $(H)$, standar deviasi $(\sigma)$ dan dividen $=0$.

2. Membangkingkan dua bilangan acak yang berdistribusi normal standar

3. Menghitung nilai estimasi harga saham pada periode yang telah ditentukan dengan persamaan (13) dan (14)

4. Membandingkan nilai estimasi harga saham tiap periode dengan nilai barrier.

5. Hitung masing-masing harga saham menggunakan persamaan (3)

6. Ulangi langkah (2) sampai langkah (5) sebanyak $\mathrm{N}$ simulasi.

7. Hitung rataan dan simpangan yang diperoleh sehingga di peroleh harga opsi barrier.

\section{METODELOGI PENELITIAN}

Jenis data yang digunakan dalam penelitian ini adalah data sekunder yang diperoleh dari www.finance.yahoo.com berupa harga penutupan dari saham PT Adhi Karya pada tanggal 5 Januari 2015 sampai 5 Mei 2017.

Langkah-langkah yang digunakan dalam penelitian ini yaitu sebagai berikut:

1. Mencari dan mengumpulkan data historis saham dari PT Adhi Karya

2. Menghitung nilai return dari harga saham penutupan pada PT Adhi Karya menggunakan persamaan (8) kemudian menghitung rata-rata return harga saham menggunakan persamaan (9)

3. Menghitung volatilitas tahunan harga opsi saham dari PT Adhi Karya dengan menggunakan persamaan (11)

4. Menentukan variabel- variabel yang diperlukan dalam mensimulasi harga opsi yaitu yaitu nilai opsi awal $\left(S_{0}\right)$, waktu jatuh tempo $(T)$, harga kesepakatan $(K)$, suku bunga bebas risiko $(r)$, nilai barrier $(H)$, dan standar deviasi $(\sigma)$.

5. Menghitung nilai opsi analitik menggunakan persamaan (4)

6. Mensimulasikan harga opsi menggunakan simulasi Monte Carlo Standar sebagai berikut:

a) Membangkitkan bilangan acak yang berdistribusi normal.

b) Menghitung nilai estimasi harga saham pada tiap periode yang ditentukan menggunakan persamaan (7)

c) Membandingkan nilai harga saham tiap periode dengan nilai barrier menggunakan persamaan (2)

d) Menghitung nilai harga opsi berdasarkan persamaan (3)

e) Ulangi langkah (a) sampai (d) sebanyak $N$ simulasi . Pada penelitian ini sampel yang digunakan adalah $N=50, N=$ 200, $N=1.000, N=10.000, N=$ 100.000, dan $N=1.000 .000$

f) Kemudian hitung rataan dan simpangan baku harga opsi sehingga diperoleh harga opsi barrier.

7. Mensimulasikan harga opsi menggunakan simulasi Monte Carlo-Antithetic Variate sebagai berikut:
a) Membangkingkan dua bilangan acak yang berdistribusi normal
b) Menghitung nilai estimasi harga saham pada periode yang telah ditentukan dengan persamaan (13) dan (14)
c) Membandingkan nilai estimasi harga saham tiap periode dengan nilai barrier.
d) Hitung masing-masing harga opsi menggunakan persamaan (3)


g) Ulangi langkah (a) sampai langkah (d) sebanyak $N$ simulasi. Sampel yang digunakan dalam penelitian ini adalah $N=50, N=200, N=1.000, N=$ $10.000, N=100.000, \operatorname{dan} N=$ 1.000 .000

e) Hitung rataan dan simpangan dari harga opsi yang diperoleh sehingga di peroleh harga opsi barrier.

8. Selanjutnya bandingkan hasil perhitungan harga opsi jual barrier down and out yang dihitung dengan simulasi Monte Carlo Standar dan simulasi Monte CarloAntithetic Variate. Perbandingan dapat dilihat dari harga opsi yang mendekati nilai opsi analitik, standar errorterkecil, dan selang kepercayaan terpendek.

\section{HASIL DAN PEMBAHASAN}

Langkah pertama yaitu menentukan nilai return saham PT Adhi Karya pada waktu $t$ dapat dihitung menggunakan persamaan (8). Sebagai contoh perhitungan return saham PT Adhi Karya pada saat $t=1$ yaitu sebagai berikut:

$$
\begin{aligned}
R_{1} & =\ln \left(\frac{3073,94}{3038,4}\right) \\
& =0,011629078
\end{aligned}
$$

Setelah tingkat pengembalian dari harga saham diperoleh maka dapat dihitung nilai rata-rata tingkat pengembalian menggunakan persamaan (9). Hasil perhitungannya sebagai berikut:

$$
\begin{aligned}
& \overline{R_{t}}=\frac{1}{n} \sum_{t=1}^{n} R_{t} \\
& =\frac{1}{567}(-0,341222807) \\
& =-0,000601804
\end{aligned}
$$

Jadi, diperoleh nilai rata-rata tingkat pengembalian harga saham PT Adhi Karya adalah $-0,000601804$.

Nilai statistika deskriptif dari data return diperoleh dengan menghitung nilai mean, variance, skewness, dan kurtosis menggunakan bantuan software Matlab sehingga diperoleh hasil seperti Tabel 1.
Tabel 1. Nilai Statistika Deskriptif Return

\begin{tabular}{|l|l|}
\hline Karakteristik & Nilai \\
\hline Mean & $-0,0006018$ \\
\hline Variance & 0,00075391 \\
\hline Skweness & 0,4324 \\
\hline Kurtosis & 8,9215 \\
\hline
\end{tabular}

Berdasarkan statistika deskriptif data return pada Tabel 4.2 menunjukkan bahwa rata-rata tingkat pengembalian PT Adhi Karya harga saham bernilai negatif atau turun. Model data return harga saham PT Adhi Karya memiliki bentuk yang tidak simetris. Hal ini ditunjukkan dengan nilai skweness positif berati data menceng ke kanan, selanjutnya ditunjukkan dengan nilai kurtosis yang cukup besar yaitu 8,9215 (lebih besar dari tiga) mengindikasikan data tidak berdistribusi normal.

Langkah selanjutnya menghitung nilai volatilitas. Volatilitas tahunan dihitung menggunakan persamaan (11) yakni:

$$
\begin{aligned}
\sigma & =\sqrt{\operatorname{var}\left(R_{t}\right) \times k} \\
& =\sqrt{0,00075391 \times 246} \\
& =0,430652916 .
\end{aligned}
$$

Maka, diperoleh volatilitas tahunan harga saham PT Adhi Karya sebesar 0,430652916.

\section{Variabel-variabel Penentuan Nilai Opsi}

Penentuan harga kontrak opsi barrier tipe Eropa tredapat variabel-variabel yang digunakan yaitu:

1. Menentukan nilai harga saham awal $\left(S_{0}\right)$

Harga saham yang digunakan adalah harga harian saham PT Adhi Karya pada tanggal 5 Januari 2015 sampai 5 Mei 2017. Data harga saham awal dapat dilihat pada Lampiran 1 yaitu pada tanggal 5 Mei 2017 yaitu sebesar Rp. 2.160

2. Menentukan nilai volatilitas $(\sigma)$

Nilai volatilitas tidak dapat diamati secara langsung dari data historis sehingga data harus diestimasi dahulu untuk menentukan nilai volatilitas. Nilai volatilitas dihitung dengan menggunakan data return harga 
saham periode 5 Januari 2015 sampai 5 Mei 2017. Nilai volatilitas yang digunakan adalah nilai volatilitas tahunan sebesar 0,430652916.

3. Menentukan tingkat suku bunga bebas risiko(r)

Tingkat suku bunga yang digunakan dalam penelitian ini adalah suku bunga yang dikeluarkan oleh Bank Indonesia sebesar $4,75 \%$.

4. Menentukan waktu jatuh tempo $(T)$

Waktu jatuh tempo diperoleh dari lamanya kontrak pada kontrak opsi yaitu selama enam bulan, sehingga waktu jatuh tempo pada penelitian ini adalah 0,5 tahun yaitu dari tanggal 5 Mei 2017 hingga 30 November 2017.

5. Menentukan harga pelaksanaan $(K)$

Harga pelaksaan atau strike price adalah suatu harga yang didapat atau ditetapkan dari kesepakatan antara penjual dan pembeli opsi. Penelitian ini menggunakan tiga harga pelaksanaan yang berbeda yaitu $K=2.000, K=2.160$, dan $K=2.300$.

6. Menentukan nilai barrier $(H)$

Batas nilai barrier adalah suatu harga yang disetujui dari kesepakatan antara penjual dan pembeli opsi. Dalam penelitian ini diambil duacontoh nilai barrier yaitu $H=1.500$ dan $H=1.650$.

\section{Perhitungan Nilai Analitik Opsi Jual Barrier Down and Out}

Perhitungan nilai analitik pada opsi jual tipe barrier down and outmengunakan persamaan (4) dengan $S_{0}=2160, K=2000, H=1500, \sigma=$ $0,430652916, r=0,0475, T=0,5 \quad$ yakni sebagai berikut:

Nilai analitik opsi $=K e^{-r T}\left(N\left(-\alpha_{2}\right)-\right.$

$$
\begin{aligned}
& N\left(-\alpha_{4}\right)+a\left(N\left(\alpha_{6}\right)-\right. \\
& \left.\left.N\left(\alpha_{8}\right)\right)\right)-S_{0}\left(N\left(-\alpha_{1}\right)-\right. \\
& N\left(-\alpha_{3}\right)+b\left(N\left(\alpha_{5}\right)-\right. \\
& \left.\left.N\left(\alpha_{7}\right)\right)\right) \\
= & 35,62592
\end{aligned}
$$

Maka, diperoleh nilai opsi analitik untuk opsi jual tipe barrier down and out untuk $K=$
2.000 dengan $H=1.500$ diperoleh hasil yaitu sebesar 35,62592.

\section{Proses dan Hasil Implementasi}

Proses dan hasil implementasi berdasarkan pada parameter yang digunakan yaitu dengan $S_{0}=2.160, K=(2.000,2.160,2.300), \mathrm{H}=$ (1.500,1.650), $\sigma=0,430652916, r=$ $0,0475, T=0,5$. Proses yang dilakukan dalam memperoleh harga nilai opsi jual barrier down and out dilakukan dengan tiga tahap. Tahapan pertama yaitu menghitung nilai harga opsi barrier down and out menggunakan Simulasi Monte Carlo Standar. Dalam proses simulasi Monte Carlo Standar menggunakan pembangkitan bilangan acak yang berdistribusi normal standar dengan bantuan software Matlab untuk memperoleh simulasi harga opsi pada waktu ke-t. Tahapan kedua adalah menghitung nilai harga opsi jual barrier down and out menggunakan simulasi Monte Carlo-Antithetic Variate. Pada simulasi metode Antithetic Variate dibangkitkan dua bilangan acak dengan tanda berlawanan. Pembangkitan dua bilangan acak menggunakan bantuan software Matlab. Selanjutnya membandingkan hasil simulasi harga opsi jual menggunakan simulasi Monte Carlo Standar dengan simulasi Monte CarloAntithetic Variate. Kemudian dilihat nilai harga opsi, standar error, dan selang kepercayaan terkecil yang dihasilkan dari simulasi Monte Carlo Standard dan Monte Carlo-Antithetic Variate.

\section{Simulasi Harga Opsi Jual Tipe Barrier menggunakan Metode Monte Carlo Standar dan Metode Monte Carlo-Antithetic Variate}

Simulasi nilai harga opsi dengan metode Monte Carlo Standar melibatkan pembangkitan bilangan acak bedistribusi normal untuk memperoleh harga opsi jual. Simulasi memerlukan pengulangan yang sangat kompleks sehingga perlu menggunakan bantuan komputer dalam perhitungannya untuk memperkirakan nilai harga opsi yang akan datang. Perhitungan proses simulasi Monte Carlo Standar menggunakan persamaan (4). Selanjutnya harga 
opsi diperoleh dengan menggunakan persamaan (3).

Simulasi Monte Carlo-Antithetic Variate merupakan perluasan dari simulasi Monte Carlo Standar dengan melibatkan pembangkitan bilangan acak untuk mensimulasi nilai harga opsi. Pada simulasi Monte Carlo-Antithetic Variate melibatkan pembangkitan dua bilangan acak untuk mendapatkan nilai varians yang lebih kecil pada harga opsi.

Dalam proses simulasi nilai saham dapat digunakan persamaan (13) dan (14). Selanjutnya bandingkan setiap simulasi dengan nilai barrier menggunakan persamaan (2) kemudian rataratakan hasil simulasi. Setelah merata-ratakan hasil simulasi kemudian menghitung harga opsi jual barrier menggunakan persamaan (3). Simulasi pada penelitian ini dilakukan sebanyak $\mathrm{N}$ iterasi yaitu $\mathrm{N}=50, \mathrm{~N}=200, \mathrm{~N}=1.000, \mathrm{~N}=$ $10.000, \mathrm{~N}=100.000$, dan $\mathrm{N}=1.000 .000$. Simulasi harga opsi menggunakan bantuan software Matlab.

Tabel 2. Perbandingan Hasil Simulasi Monte Carlo Standar dengan Simulasi Monte Carlo Antithetic Variate dengan $N=1.000 .000$

\begin{tabular}{|c|c|c|c|c|c|c|c|}
\hline & & \multicolumn{3}{|c|}{ Monte Carlo Standar } & \multicolumn{3}{|c|}{ Monte Carlo Antithetic Variate } \\
\hline & $\begin{array}{c}\text { Nilai } \\
\text { Analitik }\end{array}$ & $\begin{array}{l}\text { Harga } \\
\text { Opsi }\end{array}$ & $\begin{array}{l}\text { Standar } \\
\text { Error }\end{array}$ & $\begin{array}{c}\text { Selang } \\
\text { Kepercayaan }\end{array}$ & $\begin{array}{l}\text { Harga } \\
\text { Opsi }\end{array}$ & $\begin{array}{c}\text { Standar } \\
\text { Error }\end{array}$ & $\begin{array}{c}\text { Selang } \\
\text { Kepercayaan }\end{array}$ \\
\hline $\begin{array}{l}K=2000 \\
H=1500\end{array}$ & 35,6259 & 39,2741 & 0.0954 & $\begin{array}{c}27,3489- \\
58,6790\end{array}$ & 39,1423 & 0,0674 & $\begin{array}{c}30,7307- \\
47,5539\end{array}$ \\
\hline $\begin{array}{l}K=2000 \\
H=1650\end{array}$ & 11,3198 & 13,3569 & 0,0483 & $\begin{array}{l}7,3230- \\
19,3907\end{array}$ & 13,3267 & 0,0341 & $\begin{array}{l}9,0559- \\
17,5934\end{array}$ \\
\hline $\begin{array}{l}K=2160 \\
H=1500\end{array}$ & 73,0116 & 78,4146 & 0,1499 & $\begin{array}{c}59,6830- \\
97,1462\end{array}$ & 78,2871 & 0,1059 & $\begin{array}{c}65,0603- \\
91,5339\end{array}$ \\
\hline $\begin{array}{l}K=2160 \\
H=1650\end{array}$ & 31,2890 & 35,3849 & 0,0926 & $\begin{array}{c}23,8159- \\
46,9540\end{array}$ & 35,2596 & 0.0654 & $\begin{array}{c}27,0864- \\
43,4327\end{array}$ \\
\hline $\begin{array}{l}K=2300 \\
H=1500\end{array}$ & 117,3848 & 124,9489 & 0.2018 & $\begin{array}{l}99,7319- \\
150,1660\end{array}$ & 124,6297 & 0,1423 & $\begin{array}{r}106,8453- \\
142,4141 \\
\end{array}$ \\
\hline $\begin{array}{l}K=2300 \\
H=1650\end{array}$ & 58,4708 & 64,4175 & 0,1380 & $\begin{array}{c}47,1696- \\
81,6654\end{array}$ & 64,3901 & 0,0976 & $\begin{array}{c}52,1934- \\
76,5869\end{array}$ \\
\hline
\end{tabular}

Secara umum, terlihat pada Tabel 2.pada simulasi $\mathrm{N}=1.000 .000$ harga opsi yang dihitung menggunakan simulasi Monte CarloAntithetic Variate nilainya lebih mendekati nilai analitik dibandingkan dengan menggunakan simulasi Monte Carlo standar. Dapat dilihat pula, bahwa dengan menggunakan simulasi Monte Carlo-Antithetic Variate mampu menghasilkan standar erroryang lebih kecil dan selang kepercayaan yang lebih pendek.

\section{KESIMPULAN DAN SARAN}

Dari hasil pembahasan yang telah diuraikan sebelumnya, diperoleh suatu kesimpulan bahwa perbandingan hasil simulasi Monte Carlo Standar dengan simulasi Monte CarloAntithetic Variate menghasilkan harga opsi yang nilainya hampir sama namun, harga opsi dengan simulasi Monte Carlo-Antithetic Variate lebih mendekati nilai opsi solusi analitik daripada simulasi Monte Carlo Standar. Simulasi Monte Carlo Standar menghasilkan nilai standar error lebih besar dan selang kepercayaan yang panjang 
sedangkan pada simulasi Monte CarloAntithetic Variate menghasilkan nilai standar error lebih kecil dan selang kepercayaan yang lebih pendek. Hal ini diakibatkan karena pada simulasi Monte Carlo-Antithetic Variate terjadi teknik pengurangan varians dengan mengganti peubah acak dengan peubah acak lainya yang berkorelasi negatif. Jadi, dengan menggunakan teknik pengurangan varians diperoleh standar error yang lebih kecil dan selang kepercayaan yang lebih pendek daripada teknik biasa yaitu simulasi Monte Carlo Standar.

Saran yang dapat diberikan untuk dijadikan pertimbangan dalam penelitian selanjutnya antara lain:

1. Untuk pengembangan penelitian selanjutnya, diharapkan menentukan opsi double barrier menggunakan teknik antithetic variate.

2. Penentuan harga opsi dengan memasukkan faktor-faktor lain seperti pembagian dividen, komisi, dan pajak agar memberikan hasil yang lebih baik.

\section{DAFTAR PUSTAKA}

Artanadi, N. N. A., Dharmawan, K. \& Jayanegara, K., 2017. Penentuan Harga Beli Opsi Asia Dengan Metode Monte Carlo-Control Variate. E-Jurnal Matematika, 6(1), pp. 29-36.

Artini, N. K. A., Dharmawan, K. \& Oka, T. B., 2016. Mengestimasi Value at Risk pada Opsi Beli Tipe Asia yang Dihitung Menggunakan Metode Importance Sampling [skripsi]. Jimbaran: Universitas Udayana.

Boyle, P.P., 1977. Option A Monte Carlo Approach. Journal of Financial Economics 4:323-338.

Fabozzi, F. J., 2000. Manajemen Investasi. Jakarta: Salemba Empat.

Glasserman, P., 2004. Monte Carlo Method in Financial Engineering. New York: Springer.

Halim, A., 2005. Analisis Investasi. 2nd ed. Jakarta: Salemba Empat.
Haug, E. G., 2006. The Complete Guide to Option Pricing Formulas. 2nd ed. New York: McGraw-Hill.

Hull, J. C., 2009. Option, Futures, and Other Derivatives. 7th ed. New Jersey: Pearson Prentice Hall.

Lessy, D., 2013. Simulasi Monte Carlo dalam Penentuan Harga Opsi Barrier. Jurnal Matematika dan Pembelajaran, Volume 2, pp. 21-22.

Tandelilin, E., 2010. Portofolio dan Investasi. Yogyakarta: Kanisius.

Wang, B. \& Wang, L., 2011. Pricing Barrier Options using Monte Carlo Methods, Uppsala: Department of Mathtematics Uppsala University.

Yahoo, n.d. Yahoo Finance. [Online] Availableat:https://finance.yahoo.com/quo te/INDF.JK/history[Accessed 2 June 2017].

Yen, J. \& La, K. K., 2015. Emerging Financial Derivatives: Understanding exotic options and structured products. New York: Routledge. 